\title{
Cellular Delivery of Neurotrophin-3 Promotes Corticospinal Axonal Growth and Partial Functional Recovery after Spinal Cord Injury
}

\author{
R. Grill, ${ }^{1}$ K. Murai, ${ }^{1}$ A. Blesch, ${ }^{1}$ F. H. Gage, ${ }^{2}$ and M. H. Tuszynski ${ }^{1,3}$ \\ ${ }^{1}$ Department of Neurosciences, University of California-San Diego, La Jolla, California 92093-0608, 2Laboratory of \\ Genetics, The Salk Institute, La Jolla, California 92037, and 3Veterans Affairs Medical Center, San Diego, California 92161
}

\begin{abstract}
The injured adult mammalian spinal cord shows little spontaneous recovery after injury. In the present study, the contribution of projections in the dorsal half of the spinal cord to functional loss after adult spinal cord injury was examined, together with the effects of transgenic cellular delivery of neurotrophin-3 (NT-3) on morphological and functional disturbances. Adult rats underwent bilateral dorsal column spinal cord lesions that remove the dorsal corticospinal projections or underwent more extensive resections of the entire dorsal spinal cord bilaterally that remove corticospinal, rubrospinal, and cerulospinal projections. Long-lasting functional deficits were observed on a motor grid task requiring detailed integration of sensorimotor skills, but only in animals with dorsal hemisection lesions as opposed to dorsal column lesions. Syngenic primary rat fibroblasts genetically modified to produce
\end{abstract}

NT-3 were then grafted to acute spinal cord dorsal hemisection lesion cavities. Up to 3 months later, significant partial functional recovery occurred in NT-3-grafted animals together with a significant increase in corticospinal axon growth at and distal to the injury site. These findings indicate that (1) several spinal pathways contribute to loss of motor function after spinal cord injury, (2) NT-3 is a neurotrophic factor for the injured corticospinal projection, and (3) functional deficits are partially ameliorated by local cellular delivery of NT-3. Lesions of the corticospinal projection may be necessary, but insufficient in isolation, to cause sensorimotor dysfunction after spinal cord injury in the rat.

Key words: corticospinal; neurotrophin-3 (NT-3); spinal cord injury; locomotion; regeneration; gene therapy; sprouting
The contributions of various spinal pathways to sensory, motor, and autonomic dysfunction after spinal cord injury are incompletely understood. Impairments in voluntary motor function after spinal cord injury in humans are often attributed to disruption of corticospinal tract (CST) projections (Clark et al., 1985; Farmer et al., 1993; Nathan, 1994); therefore, experimental therapeutic interventions in animal models often focus on promoting regeneration of this pathway (Schnell et al., 1994; Bregman et al., 1995; Cheng et al., 1996). Yet investigations of the roles of various supraspinal motor projections, and the CST in particular, indicate that multiple projecting systems influence motor function. Lesions of the CST in rats, a species frequently used to study spinal cord regeneration, have variably been reported to impair skilled motor movements, such as reaching (Whishaw et al., 1993), preferred limb use (Whishaw and Kolb, 1988), and "placing" responses (reflex limb withdrawal to touch) (Bregman et al., 1995), but generally have not been reported to impair "simple" locomotion over flat surfaces (Eidelberg et al., 1989; Whishaw et al., 1993; Fehlings and Tator, 1995). On the other hand, studies in cats and nonhuman primates report that the CST is involved in voluntary modification of gait, inducing alterations in amplitude, duration, and temporal patterns of muscle activity during locomotion through both direct projections to motor neurons and modification of activity of spinal cord pattern generators (Beloozerova and Sirota, 1993; Marple-Horvat et al., 1993; Widajewicz et al., 1994; Drew et al., 1996). In humans, isolated lesions of the

\footnotetext{
Received March 11, 1997; revised May 7, 1997; accepted May 8, 1997.

This work was supported by the Hollfelder Foundation, International Spinal Research Trust, Brodie Lockard, and Veterans Affairs Research.

Correspondence should be addressed to Dr. Mark H. Tuszynski, Department of Neurosciences-0608, University of California-San Diego, La Jolla, CA 92093.

Copyright (C) 1997 Society for Neuroscience $0270-6474 / 97 / 175560-13 \$ 05.00 / 0$
}

CST can be followed by some functional recovery, although function is generally inferior to that of the prelesioned state (Nathan, 1994). Several other neuronal systems also influence locomotion. The rubrospinal tract influences movement through direct and reciprocal spinal motor projections that reflect activity of the rubro-cortico-cerebellar premotor pathway (Vinay et al., 1993; Miller and Houk, 1995). The vestibulospinal and reticulospinal tracts affect postural control and balance during locomotion, providing afferent input to premotoneuronal interneurons and ultimately influencing converging and diverse descending motor inputs and the spinal locomotor pattern generator (Dubuc, 1992; Fetcho, 1992; Marlinsky and Voitenko, 1992; Marlinsky, 1992; Perreault et al., 1993; Vinay and Grillner, 1993; Akbarian et al., 1994; Bussieres and Iwakiri et al., 1995; Grillner et al., 1995; Gossard et al., 1996; Pflieger and Cabana, 1996). Specialization in the vestibular system in particular has been important for the evolution of bipedal locomotion in humans (Spoor et al., 1994). The propriospinal tract in quadrupeds coordinates movement between forelimbs and hindlimbs (Midha et al., 1987; Whishaw et al., 1990; Fehlings and Tator, 1995). Clearly, multiple supraspinal and spinal pathways influence spinal motor and premotor neurons and local pattern generators to produce locomotion. Delineating precise roles for each pathway is challenging, yet of some importance for directing efforts to promote recovery from spinal cord injury.

The present experiment was designed to examine the contributions of spinal projection pathways to motor dysfunction after spinal cord injury, and the effects of a putative CST neurotrophic factor, neurotrophin-3 (NT-3) (Schnell et al., 1994; Giehl and Tetzlaff, 1996; Yee and O'Leary, 1996), on injury-induced alterations in spinal cord morphology and function. In the first set of experiments, animals underwent either limited lesions of the 
spinal dorsal columns, which contain $95 \%$ of the corticospinal projection (Joosten et al., 1992; Paxinos, 1995), or more extensive lesions of the entire dorsal half of the spinal cord containing corticospinal, rubrospinal, and cerulospinal projections together with some raphaespinal, propriospinal, and vestibulospinal projections. Subsequent analysis of motor function showed persistent behavioral deficits only among animals with more extensive dorsal hemisection lesions. In the second set of experiments, animals with dorsal hemisection lesions received grafts to the acute lesion site of autologous fibroblasts genetically modified to produce NT-3, or they received nonmodified fibroblasts. Function was assessed 1 and 3 months later, and results were compared with functional findings in animals that received grafts of autologous fibroblasts genetically modified to secrete NGF. Animals were then sacrificed, and the responses of injured systems to NT-3secreting and uninfected grafts were examined at the morphological level.

\section{EXPERIMENT 1: FUNCTIONAL EFFECTS OF CST LESIONS}

\section{Materials and Methods}

Adult Fischer 344 rats weighing 160-200 gm were experimental subjects. Animals were housed three per cage and had free access to food and water except during periods of functional testing (see below). Institutional guidelines for animal safety and comfort were adhered to.

In the first set of experiments, functional consequences of spinal cord lesions were characterized. Animals received limited midthoracic lesions of either the dorsal columns (containing caudally projecting corticospinal axons and rostrally projecting dorsal column sensory axons), or more extensive dorsal spinal cord hemisection lesions that interrupted multiple motor projections, including the corticospinal, rubrospinal, cerulospinal, and some raphaespinal, vestibulospinal, and propriospinal tracts (Paxinos, 1995) (Fig. 1). Resulting patterns of functional performance were examined using the following tasks: (1) conditioned locomotion over a grid (grid task), testing the ability of the rat to perform sensorimotor integration to avoid making "footfall" errors through the grid, a task that partially reflects the function of supraspinal motor projections to the spinal cord; (2) conditioned locomotion over a flat runway with detailed footprint analysis (base of support, angle of footpad rotation, and stride length), a task that reflects the integrity of both supraspinal motor projections to the cord and segmental (local) spinal reflex motor skills; and (3) ability and time to climb onto an elevated platform, a task that reflects in part connections between forelimb and hindlimb motor systems (propriospinal pathways) (Goldberger et al., 1990). Of these three tasks, the grid task is putatively the most sensitive to sensorimotor integration performance, because rats can walk on a stationary surface (task 2) or climb onto a platform (task 3 ) without the degree of sensory feedback and motor coordination that is required to accurately sense the location of a narrow grid bar, grasp the bar with the limbs, and ambulate forward (task 1). Functional capabilities on these tasks in lesioned animals were compared with those of unlesioned animals. Sensory testing was not performed, because the study focused on motor systems; assessments of general features of open field locomotion (Basso et al., 1995) were not used, because the intent of this study was to draw specific structural-functional correlates that are more readily discernible from the functional assays used.

\section{Lesion surgery}

$\mathrm{T} 7$ dorsal laminectomies were performed on rats deeply anesthetized with a mixture $(2 \mathrm{ml} / \mathrm{kg})$ of ketamine $(25 \mathrm{mg} / \mathrm{ml})$, rompun $(1.3 \mathrm{mg} / \mathrm{ml})$, and acepromazine $(0.25 \mathrm{mg} / \mathrm{ml})$. The dura was opened, and limited dorsal column $(n=8)$ or more extensive bilateral dorsal hemisection lesions $(n=7)$ were performed using a fine-tipped glass-pulled aspiration device (Tuszynski et al., 1996). To make dorsal column lesions, the dorsal cord midline was identified and superficially incised with microscissors. The aspiration device, with a 22 ga core diameter, was then used to extend the lesion laterally to the lateral edges of the dorsal columns and ventrally to the level of the CST where it lies just dorsal to the central gray matter and central spinal canal. The CST was then aspirated fully at the T7 level; the transition from CST to dorsal portion of the central gray matter was readily identifiable as a distinct color change from white to gray matter. The last corticospinal fibers conspicuously adhered to the aspiration device tip and literally lifted away from the central gray matter, marking complete interruption of corticospinal fibers and arrival to a point immediately dorsal to the mid-dorsoventral axis of the cord. The aspiration procedure was extended slightly more ventrally and laterally to ensure resection of all dorsal CST axons. Lesion extent was verified by complete interruption of anterograde transport of WGA-HRP injected into the hindlimb sensorimotor cortex (see below) and by examination of serial Nissl-stained sections. To perform dorsal hemisection lesions, the dorsal columns and dorsal CST were removed as indicated above. Using the dorsal column/corticospinal lesion as a guide for the desired dorsoventral depth of the lesion, the lesion was extended laterally to remove the lateral aspects of the cord bilaterally. After the operation, animals were kept warm, placed on beds of sawdust, and given manual bladder evacuation for a period of $\sim 10 \mathrm{~d}$ and intramuscularampicillin ( $25 \mathrm{mg}$ twice per day) to prevent and treat urinary tract infections. Animals regained automatic neurogenic bladder function after 5-10 d.

\section{Functional testing}

Functional testing began 1 month after surgical lesions were placed and was repeated 2 months after surgery. Only healthy animals were included in functional analyses. Functional testing was based on methods reported by Goldberger et al. (1990) and Kunkel-Bagden et al. (1993). Results in lesioned animals were compared with findings in eight intact animals.

Grid locomotion (wire grid task). Animals were required to navigate across a $150 \mathrm{~cm}$ plastic grid runway containing $40 \times 40 \mathrm{~mm}$ holes to reach a food reward, after food deprivation for $48 \mathrm{hr}$ (no more than $10-15 \%$ loss of body weight). After $5 \mathrm{~d}$ of pretraining on the grid, subjects underwent 5 more days of testing, four trials per day. Footfalls (failure to grasp a rung resulting in drop of the foot below the plane of the grid) made while crossing the grid on the last day of testing were quantified using video monitoring. Data were presented as number of footfalls to cross the platform averaged across the four trials on the final day of testing.

Platform locomotion with footprint analysis. Animals were placed on an 8 -cm-wide $\times 8$-foot-long platform with a food reward at the end. During $5 \mathrm{~d}$ of training on the runway, rats learned to walk toward the food reward, thereby producing continuous locomotion. Animals were tested for 5 additional days after the hind paws were inked (left, blue; right, red), and they ambulated on white paper. Each footprint consisted of the paired footprint pads with five toe prints. A total of 10 footprint pairs were examined from the final day of testing, using sets of footprints containing at least three consecutive strides. The following measurements were made: (1) stride length, the distance between foot pads on two consecutive footprints; (2) base of support, distance between right and left foot; and (3) angle of rotation, the angle of intersection between lines defined by the angle of the footpad and toes, drawn according to standardized criteria (Kunkel-Bagden et al., 1993). Ten samples from each subject were analyzed, and individual subject means were determined.

Elevated platform task. The forelimbs of the rats were placed on a Velcro pad of a platform located 18 inches above ground level. The latency to climb onto the top of the platform was measured. Intact subjects normally climb onto the platform with $\sim 1$ sec latency, using their hindlimbs to assist the climb onto the platform. After $5 \mathrm{~d}$ of pretesting (three trials/day), latencies were quantified from three additional trials per day conducted over a $3 \mathrm{~d}$ period. Results from the nine total trials were averaged and compared. Comparisons between groups were made using ANOVA with post hoc Fisher's least square difference.

Lesion completeness was verified by anterograde tracing of the CST and Nissl staining at the conclusion of functional testing. For anterograde tracing of the corticospinal projection, $300 \mathrm{nl}$ of a $4 \%$ solution of wheat germ agglutinin-conjugated horseradish peroxidase (WGA-HRP) (Sigma, St. Louis, MO) was injected through pulled-glass micropipettes ( $40 \mu \mathrm{m}$ internal diameter) into each of 12 sites spanning the rostrocaudal extent of the rat sensorimotor cortex (Paxinos and Watson, 1986) using a PicoSpritzer II (General Valve, Fairfield, NJ). Air-driven pulses of 15 $\mathrm{nl}$ per pulse, 20 pulses per site were delivered with a 2 sec latency between pulses. The micropipette tip remained in place for $30 \mathrm{sec}$ before withdrawal. Animals were transcardially perfused $48 \mathrm{hr}$ later with $1 \%$ paraformaldehyde $1.25 \%$ glutaraldehyde followed by $10 \%$ buffered sucrose. Thirty-five-micrometer-thick sections were cut in the sagittal plane and divided into a series of six sections. Three of every six sections were 
reacted with a modification of the tetramethyl benzidine (TMB) method of Mesulam (1978), and the remaining sections were Nissl-stained. TMBreacted sections were viewed using a dark-field condenser attached to an Olympus BM-1 microscope. Lesion completeness in animals that underwent dorsal column lesions was verified by complete interruption of WGA-HRP transport in TMB-reacted sections and by loss of all dorsal column white matter on Nissl-stained sections. Lesion completeness in animals that underwent dorsal hemisection lesions was similarly determined by loss of all WGA-HRP transport and by loss of dorsal spinal cord white and gray matter on Nissl-stained sections visualized in the coronal plane.

\section{Results}

Assessment of lesion completeness by WGA-HRP labeling and Nissl staining indicated complete interruption of corticospinal pathways in seven of eight animals that underwent dorsal column lesions and all animals that underwent dorsal hemisection lesions (Fig. 1). The single animal with an incomplete lesion was not included in analysis of functional outcomes.

Deficits lasting for at least 2 months were found on the grid task in animals that received dorsal hemisection lesions but not dorsal column lesions alone (Fig. $2 a$ ). Functional deficits did not occur on runway locomotion tasks in either lesioned group (Fig. $2 b-d$ ) or on the elevated platform task (mean latency $=1.1 \pm 0.3 \mathrm{sec}$ in intact animals, $1.2 \pm 0.2 \mathrm{sec}$ in animals with dorsal column lesions, and $1.2 \pm 0.1 \mathrm{sec}$ in animals with dorsal hemisection lesions; $p=0.74$ ). These findings indicate that interruption of several supraspinal motor systems contained within the dorsal half of the rat spinal cord, including the CST, does not result in lasting loss of several conditioned motor tasks; however, the task that most sensitively assesses sensorimotor integration, the grid locomotion task, shows long-term disruption after dorsal hemisection lesions. Isolated lesions of the corticospinal projection do not result in motor or sensorimotor impairments.

\section{EXPERIMENT 2: EFFECTS OF CELLULARLY DELIVERED NT-3 ON THE LESIONED SPINAL CORD}

\section{Materials and Methods}

Results of the preceding experiment indicate that combined lesions of several dorsal spinal cord motor systems can cause specific long-lasting sensorimotor functional deficits. Experiment 2 was designed to examine the effects of a putative spinal cord neurotrophic factor, NT-3, on morphology and function after injury. A hypothesis suggested from the results of Experiment 1 is that disruption of corticospinal projections may be necessary but not sufficient in isolation to induce long-lasting sensorimotor dysfunction, as previous electrophysiological studies in humans suggest (Netz and Homberg, 1992). NT-3 is diversely expressed in the CNS (Maisonpierre et al., 1990, 1991), and corticospinal motor neurons in sensorimotor cortex of the rat express the specific NT-3 receptor trkC (Merlio et al., 1992; Frisen et al., 1993; Muragaki et al., 1995; Yee and O'Leary, 1996). Previously it has been reported that a single injection of NT-3 promoted sprouting of corticospinal axons after spinal cord injury (Schnell et al., 1994), that NT-3 infusions rescued degenerating corticospinal motor neurons (Giehl and Tetzlaff, 1996), and that NT-3 contributes to development of the corticospinal projection (Yee and O'Leary, 1996). In addition to its putative effects on the corticospinal projection, NT-3 also rescues injured neurons of the locus ceruleus (Arenas and Persson, 1994). Cerulospinal projections constitute the sole source of noradrenergic input to the spinal cord (Paxinos, 1995) and may therefore influence spinal cord function as well. Thus, adult rats underwent dorsal hemisection lesions as described in Experiment 1. Experimental subjects then received grafts to the acute lesion cavity of syngenic fibroblasts genetically modified to produce NT-3 $(n=21)$. Control subjects received either grafts of primary nontransduced fibroblasts $(n=22)$ or grafts of NGF-producing fibroblasts $(n=8)$, a neurotrophic factor that promotes robust growth of (1) primary spinal afferent sensory systems of the dorsolateral fasciculus, (2) cerulospinal axons, and (3) ventral horn motor axons (Tuszynski et al., 1996, 1997). The NGF group served as a control group of subjects that received a neurotrophin other than NT-3. One month and 3 months after the
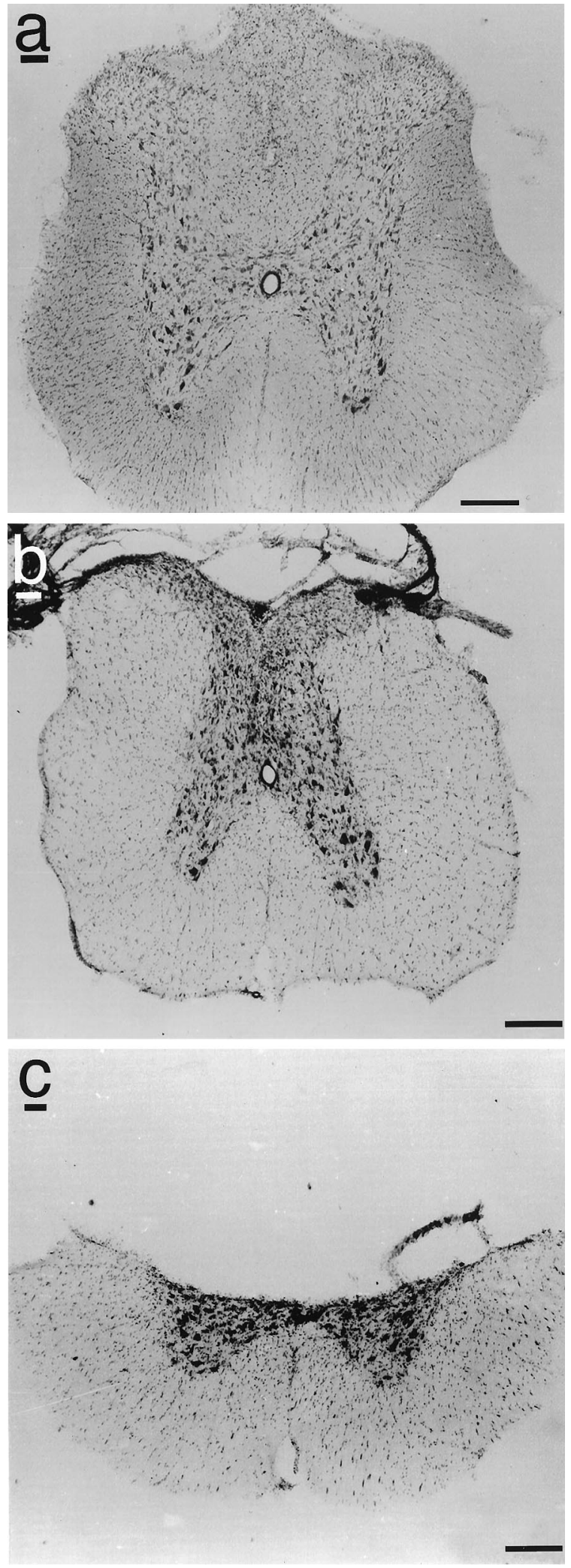

Figure 1. Examples of (a) intact spinal cord, $(b)$ dorsal column lesion of spinal cord, and $(c)$ dorsal hemisection lesion of spinal cord at the midthoracic level. Scale bars, $400 \mu \mathrm{m}$.

operation, rats underwent functional testing on the grid task, platform task with footprint analysis, and elevated platform. At the completion of functional testing, animals were sacrificed and examined for growth 

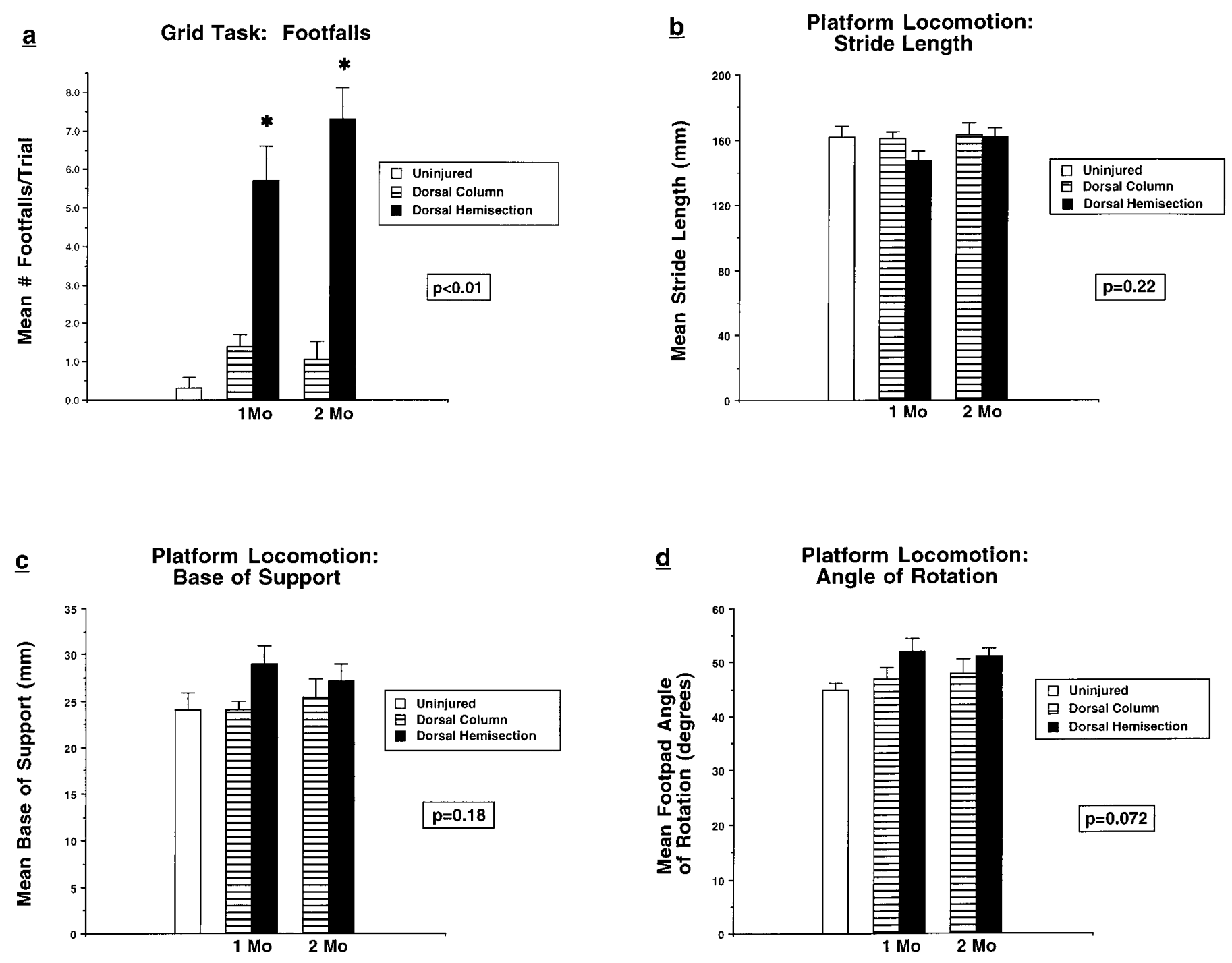

Figure 2. Functional effects of spinal cord lesions. $a$, Grid task. Rats with dorsal hemisection lesions but not dorsal column lesions show persistent functional deficits reflected by a significant increase in the number of footfalls (ANOVA, $p<0.01$ ). $b-d$, Platform locomotion. Rats with dorsal hemisection lesions and dorsal column lesions do not show significant deficits in stride length (ANOVA, $p=0.22$ ), base of support (ANOVA, $p=0.18$ ), or angle of rotation (ANOVA, $p=0.072$ ).

responses in the injured region. Lesion completeness was determined on Nissl-stained sections and anterograde WGA-HRP labeling. Growth of the lesioned CST was determined by examining and quantifying WGAHRP labeling in 10 NT-3-grafted and 15 uninfected fibroblast controlgrafted animals. Growth responses from serotonergic, cerulospinal, and local motor systems were determined by immunolabeling (in eight NT3 -grafted and eight uninfected fibroblast control-grafted animals).

Primary syngenic Fischer 344 rat fibroblasts were genetically modified to produce and secrete human NT-3 as described previously (Senut et al., 1995). Briefly, the 908 bp coding sequence for human NT-3 was inserted in a Moloney leukemia virus retroviral vector lacking the gag, pol, and env genes, and $10-15 \mu \mathrm{g}$ of plasmid DNA was transfected into the PA317 amphotropic producer cell line (packaging line) by lipofection. Conditioned medium (CM) from these cultures was used to infect primary fibroblasts. In vitro production of human NT-3 mRNA was verified by Northern blot, and production of biologically active protein was verified by a significant increase in numbers of the TH-immunolabeled neurons in cultures of embryonic day 14 fetal anterior rhombencephalon by CM from cultures of NT-3-transfected cells compared with CM from control-transfected cells $(p<0.05)$. Control fibroblasts were not genetically modified; these cells were used in grafts in control-lesioned subjects. Thus, cells in control subjects differed from NT-3-transfected cells by only a single set of genes. Transduced fibroblasts (NT-3 or control), $2.5 \times 10^{6}$, were suspended in 2 $\mathrm{ml}$ of a chilled liquid solution of Type I rat tail collagen (Sigma) as described previously (Tuszynski et al., 1996). After incubation for $48 \mathrm{hr}$ at $37^{\circ} \mathrm{C}$, the collagen/cell mixture was cut into small pieces and grafted into in vivo T7 spinal cord dorsal hemisection lesion cavities in adult Fischer 344 rats $(n=21)$. Control subjects received either (1) grafts of primary nontransduced fibroblasts ( $n=22$ animals), (2) lesions alone, without grafts $(n=6)$, or (3) grafts of NGF-producing fibroblasts $(n=8)$ (for description of methods, see Tuszynski et al., 1996).

\section{Anterograde labeling of the CST projection and quantification of CST growth after injury}

Methods used to inject WGA-HRP are described in Experiment 1. To measure the amount of CST growth in lesioned subjects, WGA-HRP granules were quantified using National Institutes of Health (NIH) Image software. Measurements were controlled for differences in efficiency of WGA-HRP labeling between animals (see below). Labeling was performed in $10 \mathrm{NT}$-3-grafted animals and 15 control-lesioned animals by quantifying the density of WGA-HRP reaction product under dark-field illumination at the level of the lesioned CST ( $0 \mathrm{~mm})$, and 4, 8 , and $12 \mathrm{~mm}$ distal to the most caudal aspect of the lesioned CST. Any labeling artifact was edited out of sections before quantification. The number of pixels occupied by reaction product in every labeled section 
was quantified using N IH Image software on a video image of each $100 \times$ magnified section transmitted by a high-resolution Sony CCD camera. Thresholding values were chosen that maximized contrast between reaction product and background and were held constant between all subjects. A fixed box size of $552 \times 436$ pixels at $100 \times$ magnification corresponding to a sample area of $0.24 \mathrm{~mm}^{2}$ was used to sample each subject. Total labeled pixels at each distance from the lesioned CST were quantified in every HRP-labeled section (every 9 of 10 sagittal-sectioned sections per animal) to generate the total density of sprouted CST fibers at each distance from the transected CST. To correct for differences in HRP labeling efficiency between animals, a baseline labeling density measurement (BLDM) was established. To determine the BLDM, the density of the labeled CST was measured at a point $1.5 \mathrm{~cm}$ rostral to the lesion site in each subject. Then the pixel values at each level $(0,4,8$, and $12 \mathrm{~mm}$ distal to corticospinal lesion) were divided by the animal's own BLDM compensation factor. These corrected values were then compared between animals to determine a specific and direct measurement of CST growth. The presence of significant differences in growth among groups was determined by ANOVA.

\section{Immunolabeling}

Animals were transcardially perfused with $100 \mathrm{ml}$ of cold $0.1 \mathrm{M}$ PBS followed by $300 \mathrm{ml}$ of $4 \%$ paraformaldehyde in PBS. Spinal cords were removed, post-fixed overnight in $4 \%$ paraformaldehyde in PBS, and then left for $3 \mathrm{~d}$ in phosphate buffer (PB) containing $30 \%$ sucrose at $4^{\circ} \mathrm{C}$. Sagittal sections were cut at $35 \mu \mathrm{m}$ intervals with a cryostat. Every sixth section was immediately mounted on glass slides for Nissl staining. Remaining alternate sections were processed for immunocytochemical labels for the low-affinity p75 NGF receptor (monoclonal IgG-192 antibody at 1:100 dilution; gift of Dr. C. E. Chandler, Department of Neurobiology, Stanford University), neurofilament (NF) [RT97 monoclonal antibody from Boehringer Mannheim (Mannheim, Germany) against $200 \mathrm{kDa} N F$ at 1:250 dilution)], choline acetyltransferase (ChAT) (for cholinergic fibers; polyclonal rabbit antibody at 1:5000 dilution; gift of Dr. L. G. Hersh, Department of Biochemistry, University of Kentucky), tyrosine hydroxylase (TH) (for dopaminergic and noradrenergic fibers; monoclonal antibody from Incstar at 1:1000 dilution), dopamine $\beta$ hydroxylase (DBH) (for noradrenergic fibers; polyclonal rabbit antibody from Eugene Tech at 1:3000 dilution), serotonin (5-HT) (polyclonal rabbit antibody from Eugene Tech at 1:1000 dilution), calcitonin generelated peptide (CGRP) [for sensory fibers; polyclonal rabbit antibody from Chemicon (Temecula, CA) at 1:8000 dilution] (Skofitsch and Jacobwitz, 1985; Harmann et al., 1988; McNeill et al., 1991), and glial fibrillary acidic protein (GFAP) (monoclonal antibody from Boehringer Mannheim at 1:250 dilution). All immunocytochemical labeling was performed by (1) incubating free-floating sections for $24 \mathrm{hr}$ in primary antibody solution in $0.1 \mathrm{M}$ Tris-saline containing $1 \%$ blocking serum and $0.25 \%$ Triton X-100; (2) incubation for $1 \mathrm{hr}$ with biotinylated goat anti-rabbit IgG (for polyclonal antibodies) or biotinylated horse antimouse IgG (for monoclonal antibodies; Vector Laboratories, Burlingame, CA) diluted 1:200 with Tris-saline containing 1\% blocking serum; (3) $1 \mathrm{hr}$ incubation with avidin-biotinylated peroxidase complex (Vector Elite Kit) diluted 1:1000 with Tris-saline containing 1\% blocking serum; and (4) treatment for 3-15 min with $0.05 \%$ solution of $3.3^{\prime}$ diaminobenzidine, $0.01 \% \mathrm{H}_{2} \mathrm{O}_{2}$, and $0.04 \%$ nickel chloride in $0.1 \mathrm{M}$ Tris buffer. Immunolabeled tissue sections were mounted onto gelatin-coated glass slides, air-dried, dehydrated, and covered with Permount and glass coverslips. Sections were examined microscopically for graft survival and lesion extent. Immunolabeled sections were examined to determine the phenotype and extent of fiber penetration within grafts.

\section{Double-label immunofluorescence confocal microscopy}

To identify the nature of host/graft interactions that might influence axonal penetration into the intraspinal cell grafts, double-labeling for NF and GFAP was performed in four animals (two NT-3 and two uninfected fibroblast control grafts). Subjects were perfused with $4 \%$ paraformaldehyde in $0.1 \mathrm{M} \mathrm{PB}$. Spinal cords were removed and serially sectioned in the sagittal plane on a cryostat at $35 \mu \mathrm{m}$ intervals. Sections were rinsed $3 \times 10$ min each in TBS $(0.1 \mathrm{M})$. Sections were incubated in TBS $+5 \%$ normal horse serum $+0.25 \%$ Triton- $X$ for $1 \mathrm{hr}$ and then transferred into the first primary antibody directed against NFs [monoclonal RT97 antibody at 1:175 dilution (Boehringer Mannheim)] and incubated overnight at $4^{\circ} \mathrm{C}$ on a rotating platform. The following day, sections were rinsed $3 \times 10 \mathrm{~min}$ each in TBS $+0.25 \%$ Triton- $X$ and then incubated in horse anti-mouse biotinylated secondary (1:200; Jackson Immunochemicals, West Grove, PA) for
$2.5 \mathrm{hr}$. Sections were then rinsed $3 \times$ in TBS and incubated in dichlorotriazinylamino fluorescein (DTAF)-streptavidin as a tertiary (1:300; Jackson Immunochemicals) for an additional $2.5 \mathrm{hr}$. Sections were rinsed again in TBS and then blocked in TBS $+5 \%$ normal donkey serum for $1 \mathrm{hr}$. Sections were then incubated in the second primary, GFAP (polyclonal, 1:750; DAKO, Carpinteria, CA), overnight at $4^{\circ} \mathrm{C}$. The following day, sections were incubated in secondary donkey anti-rabbit-Texas Red (1:200; Jackson Immunochemicals) for $2.5 \mathrm{hr}$ and then rinsed. Doubleimmunolabeled sections were mounted onto glass slides and coverslipped with FluoroMount-G (Southern Biotechnology, Alabaster, AL) and observed using absorption spectra filters of bandpass 490 (DTAF) and 545 (rhodamine). Sections were observed and imaged using a Bio-Rad MRC1024 confocal microscope (Bio-Rad, Richmond, CA) to examine the association of reactive glial processes to neuritic patterns of labeling.

\section{In vivo transgene expression}

The ability of grafts of human NT-3-expressing cells to maintain transgene expression over time in vivo was assessed in separate animals by performing RT-PCR on fresh dissections of NT-3-producing cell grafts to nonlesioned spinal cords. RNA was isolated from fresh cord using the method of Chomczynski and Sacchi (1987). One microgram of total RNA was reverse-transcribed according to manufacturer's instructions (Boehringer Mannheim) using random primers. The $50 \mu \mathrm{l}$ PCR reaction contained $1 / 10$ of first-strand synthesis, $0.5 \mu \mathrm{g}$ of each primer, $1.5 \mathrm{~mm}$ $\mathrm{MgCl}_{2}, 50 \mathrm{~mm} \mathrm{KCl}, 10 \mathrm{~mm}$ Tris-HCl, pH 9.0, 0.1\% Triton X-100, $0.2 \mathrm{~mm}$ dNTP, and $2.5 \mathrm{U}$ Taq polymerase (Promega, Madison, WI), and amplification was performed for $35 \mathrm{cycles}\left(60 \mathrm{sec}\right.$ at $94^{\circ} ; 30 \mathrm{sec}$ at $60^{\circ} \mathrm{C} ; 60 \mathrm{sec}$ at $72^{\circ} \mathrm{C}$ ). Sequences of primers are published elsewhere (Senut et al., 1995). Ten microliters of each PCR reaction were separated in a $2 \%$ agarose gel. Grafts in two animals each were tested at time points of 2 weeks, 1 month, and 3 months, and two additional animals were sampled at 6 months to gauge the extent of prolonged in vivo transgene expression.

\section{Statistics}

Differences in quantitative variables between groups were tested by ANOVA. Post hoc differences were assessed by Fisher's least significant difference. For all data collection, experimenters were blinded to group identities.

\section{Results}

\section{Function}

On functional testing, recipients of NT-3-secreting grafts showed significant recovery on the grid task compared with uninfected fibroblast control graft recipients (Fig. 3) at 1 and 3 months after grafting $(p<0.01)$. Recipients of NGF-secreting grafts did not show functional recovery (Fig. 3), indicating the specificity of the functional effect to recipients of NT-3-secreting cell grafts. NT-3 graft recipients performed significantly better than the other lesioned groups on the grid task but also differed significantly from intact animals. As observed in the first set of experiments above, deficits on platform motor tasks that did not require extensive sensorimotor integration were not detected, nor did NT-3 grafts impair these functions (Fig. 4). Similarly, deficits were not present on the elevated platform task (data not shown).

\section{Histology}

Findings were investigated in all NT-3- and control-grafted animals [findings in NGF-grafted animals have been reported previously and are not repeated here (Tuszynski et al., 1994, 1996, 1997)]. Grafts of NT-3-secreting and control uninfected fibroblasts survived in the lesion cavity through the 3 month grafting period (Fig. 5). WGA-HRP labeling of the injured corticospinal projection demonstrated significant growth of CST axons in recipients of NT-3-secreting grafts at and distal to the spinal cord lesion site compared with control animals (Figs. 6, 7). Growth was significant for up to $8 \mathrm{~mm}$ distal to the lesion site. A statistically significant increase in growth beyond this point, at $12 \mathrm{~mm}$, was not observed. Of note, corticospinal axons extended through 


\section{Grid Task: Footfalls}

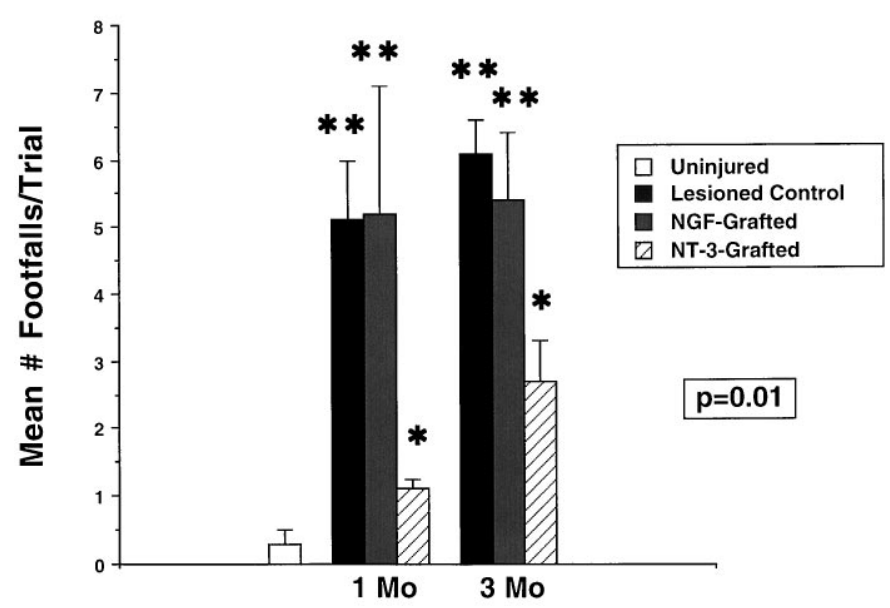

Figure 3. Functional recovery in recipients of NT-3-secreting grafts. Functional recovery in NT-3-grafted subjects is observed on the grid task compared with control-grafted and NGF-grafted subjects (ANOVA, $p=$ 0.01 ). NT-3-grafted subjects perform significantly better than control- and NGF-grafted subjects at 1 and 3 months after grafting (post hoc Fischer's test), but NT-3 subjects also differ significantly from intact subjects. **, Significant difference from NT-3-grafted and uninjured animals; *, significant difference from uninjured animals. Comparison of degree of recovery in NT-3 subjects at 1 and 3 months after lesion shows no significant difference (post hoc Fischer's test). Functional testing results were replicated in two separate series of experiments.

spinal cord gray matter but not into white matter tracts. Furthermore, only the lesioned dorsal CST appeared to extend axons in response to the presence of the NT-3-secreting graft, whereas an enhancement in sprouting of the unlesioned ventral CST was not observed. The latter finding was evident in two ways. First, WGA-HRP-labeled axons of the ventral CST were not observed to traverse the ventral white to gray matter interface, whereas numerous axons crossed the interface between the dorsal CST and gray matter. Second, the number of WGA-HRP-labeled axons in the ventral CST did not differ between NT-3-grafted and control uninfected fibroblast-grafted subjects: $5.9 \pm 1.5$ axons per section were labeled in the ventral CST in NT-3-grafted subjects compared with $5.1 \pm 1.2$ axons per section in control-lesioned subjects ( $p=0.83$ ). Thus, axons of the lesioned dorsal CST rather than axons of the intact ventral CST responded to NT-3-secreting grafts, and contributions of the CST to functional recovery, if any, were likely derived from the dorsal rather than ventral CST. In some cases, WGA-HRP labeling revealed distinct growth from the tips of lesioned CST axons at the injury site to points distal, representing regeneration of injured axons. In other cases, WGAHRP labeling that occurred at and distal to the injury site was punctate in nature (Fig. 6) and could represent either regeneration or sprouting of axons near the injury site.

\section{Axonal/glial associations}

In no case did corticospinal axons penetrate NT-3-secreting or control grafts. This lack of CST penetration into grafts could result either from glial/inflammatory responses at the host/graft interface that blocked growing axons or from components of the graft substrate that were nonpermissive for axon growth. To determine the association of spinal cord axons with glia at the lesion site and at the host/graft interface, sections double-labeled for NF and GFAP were examined. At the host/graft interface,

\section{a Platform Locomotion: Stride Length}

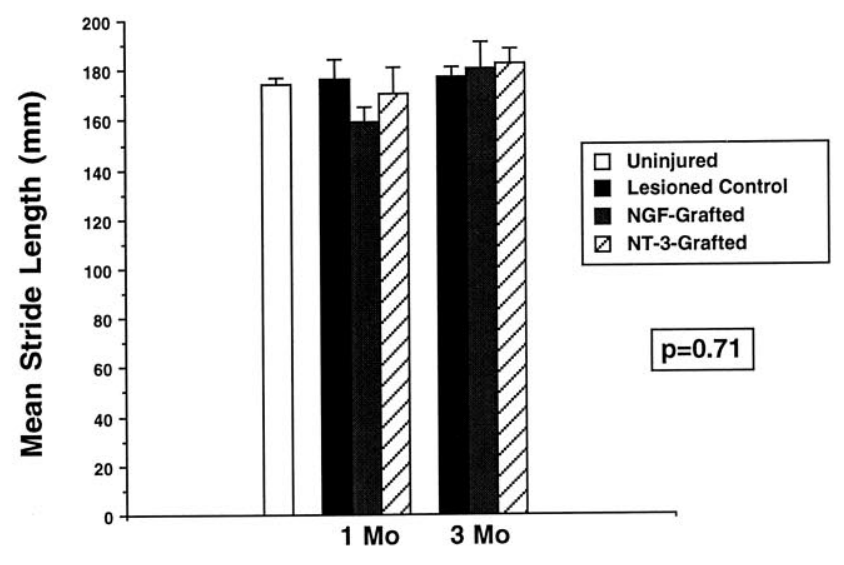

$\underline{\mathbf{b}}$

\section{Platform Locomotion: Base of Support}

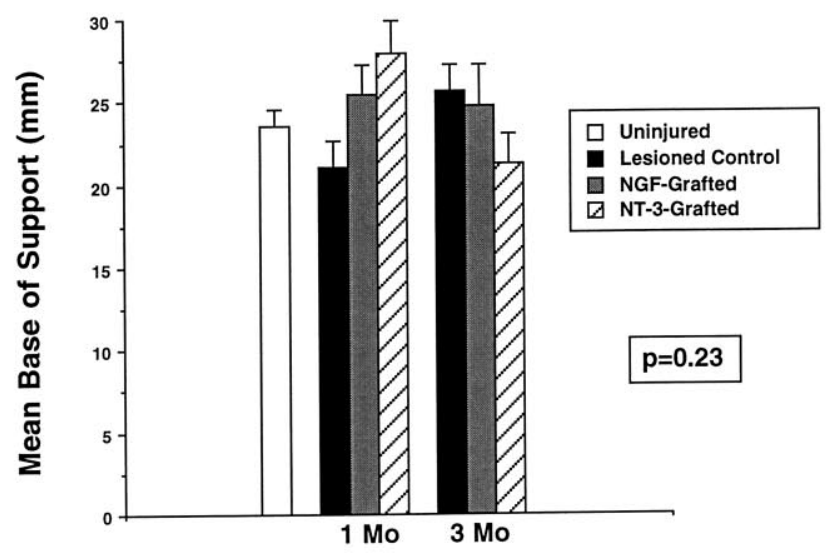

$\underline{\text { C }}$
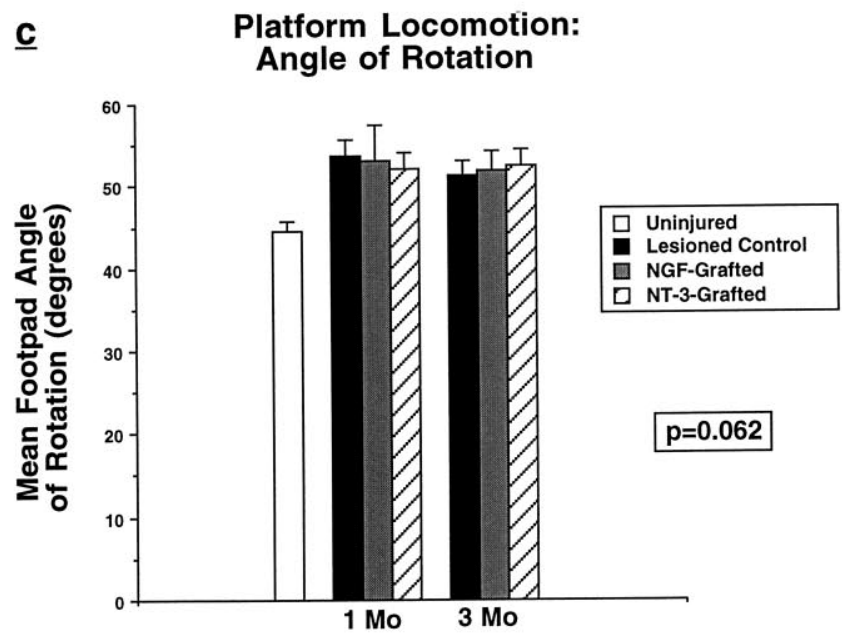

Figure 4. Function on tasks unaffected by dorsal hemisection lesions. Platform locomotion $(a-c)$ is unaffected by the experimental manipulations, indicating that grafts do not alter function on these tasks.

significant upregulation of GFAP expression was observed (Fig. 8); however, several NF-labeled processes readily penetrated regions of GFAP upregulation to pass through the glial "barrier" and directly penetrate both NT-3-secreting and control grafts. Indeed, both NF- and GFAP-IR processes continued to penetrate grafts for some distance, and NF- and GFAP-IR processes 

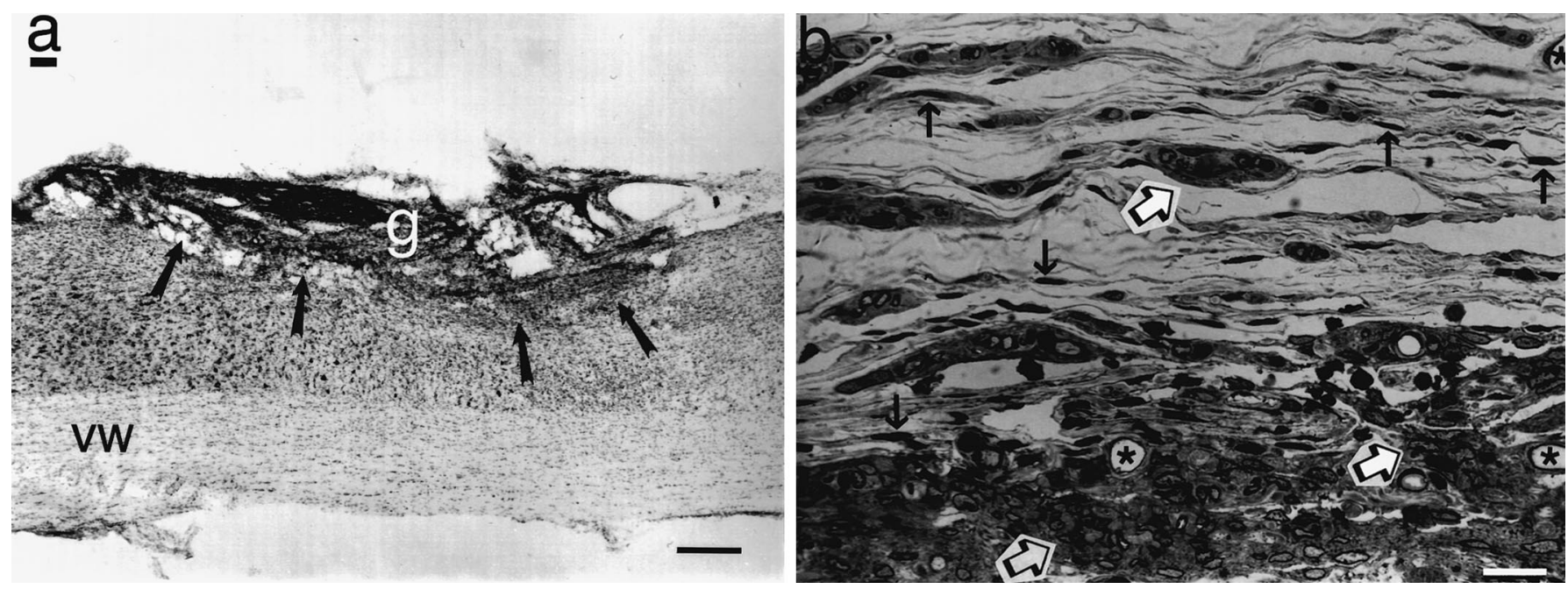

Figure 5. Histology of grafts. $a$, Appearance of 3-month-old NT-3 graft filling lesion site (arrows). Nissl stain, sagittal section. $g$, Graft; $v w$, ventral white matter. Scale bar, $100 \mu \mathrm{m} . b, 1.5 \mu \mathrm{m}$ semithin section of NT-3 graft stained for Giemsa shows numerous surviving fibroblasts (black arrows), clusters of both myelinated and unmyelinated axons (open arrows), blood vessels (stars), and islands of collagen. Control grafts do not differ in appearance (not shown). Scale bar, $12 \mu \mathrm{m}$.

were often co-associated within grafts (Fig. 8). In other instances, NF-IR processes penetrated grafts without specific co-association with GFAP-IR processes. The overall nature of the astroglial response did not differ between NT-3 and control graft recipients. Thus, glial responses at the host/graft interface did not present an impenetrable wall to lesioned axons; on the contrary, in some instances astrocytic processes were intimately co-associated with penetrating axons.

\section{Responses of other axonal phenotypes to NT-3-secreting cell grafts}

Immunolabeling revealed penetration of some axonal phenotypes into both NT-3-secreting and control grafts but no significant augmentation of this growth in NT-3-secreting graft recipients (Fig. 9). NF immunolabeling revealed modest axonal growth into both graft types (Fig. 9a,b). Specific labeling to identify the transmitter phenotype of penetrating axons indicated that most originated from primary sensory afferents, evidenced by immunolabeling for CGRP (Fig. 9c,d) and Substance P, with occasional responses from 5-HT- (Fig. 9e,f), TH- (Fig. 9g,h), and DBHlabeled axons. No significant sprouting responses were observed from ChAT-immunolabeled axons into either NT-3 or control grafts. Alterations in immunolabeling patterns of these markers in host regions surrounding the graft were not observed, distinct from the specific augmentation in growth of WGA-HRP-labeled CST axons in NT-3 graft recipients (Figs. 6, 7). There were no differences in axonal growth within the host cord when lesioned nongrafted animals and lesioned fibroblast-grafted animals were compared.

In vivo expression of the human NT-3 transgene for the 3 month period of this experiment, and indeed for at least 6 months in vivo, was verified by RT-PCR performed on fresh grafts placed in unlesioned rat spinal cords (Fig. 10). Because these measurements were made in grafts to the unlesioned cord, the possibility exists that expression might have differed in grafts to lesioned spinal cords.

\section{DISCUSSION}

Results from these two sets of experiments indicate that (1) lesions of the dorsal CST alone do not cause lasting motor or sensorimotor functional deficits, (2) injury to multiple descending motor systems in the rat are required to induce lasting deficits in sensorimotor function, (3) cellularly delivered NT-3 induces significant and sustained growth of corticospinal axons after spinal cord injury, and (4) cellularly delivered NT-3, unlike cellularly delivered NGF, improves sensorimotor functional deficits after spinal cord injury. These findings suggest that injuries to corticospinal projections are not solely responsible for sensorimotor deficits but contribute to the severity of such deficits, and that these deficits can be partially ameliorated by cellular delivery of NT3.

The specific role and importance of various supraspinal motor projections in the regulation of locomotor performance and the effects of lesions of these projections have been studied extensively. As outlined in the introductory remarks, locomotor functions have been attributed to corticospinal, rubrospinal, vestibulospinal, reticulospinal, and propriospinal systems (Clark et al., 1985; Midha et al., 1987; Whishaw and Kolb, 1988; Whishaw et al., 1990; Bussieres and Dubuc, 1992; Fetcho, 1992; Marlinskii and Voitenko, 1992; Marlinsky, 1992; Beloozerova and Sirota, 1993; Farmer et al., 1993; Marple-Horvat et al., 1993; Perreault et al., 1993; Vinay and Grillner, 1993; Vinay et al., 1993; Whishaw et al., 1993; Akbarian et al., 1994; Nathan, 1994; Spoor et al., 1994; Widajewicz et al., 1994; Bregman et al., 1995; Fehlings and Tator, 1995; Grillner et al., 1995; Iwakiri et al., 1995; Miller and Houk, 1995; Drew et al., 1996; Gossard et al., 1996; Pflieger and Cabana, 1996). In the present study, we show that interruption of dorsal corticospinal systems together with spinogracilar projections do not cause loss of several specific and quantifiable conditioned motor tasks. Even more extensive lesions that interrupt all dorsal supraspinal projections, including the corticospinal, rubrospinal, and cerulospinal and portions of the raphaespinal, vestibulospinal, and propriospinal projections, produce lasting deficits on only an integrative sensorimotor task, the grid task. Thus, multiple pathways contribute to regulation of locomotor function in the spinal cord. Previous studies have reported that more extensive lesions that remove the dorsal halves of the spinal cord bilaterally plus the ventral spinal cord unilaterally, a so-called "dorsal overhemisection lesion," result in deficits on several motor as well as sensorimotor tasks (Bregman et al., 1995). Indeed, severe loco- 

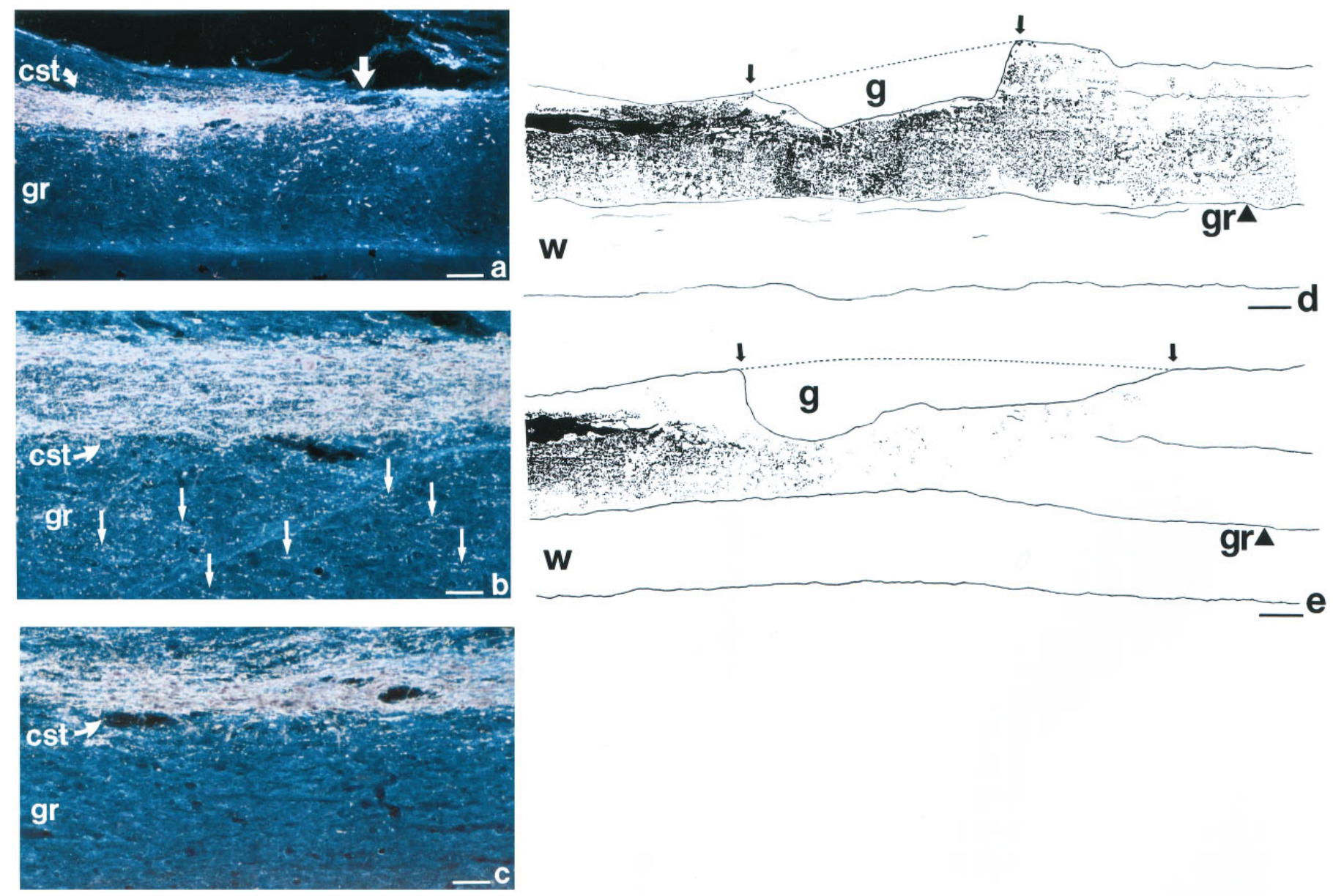

Figure 6. WGA-HRP labeling. a, Low-magnification view of WGA-HRP labeling of lesioned corticospinal tract (cst) in NT-3-grafted animal that underwent spinal cord dorsal hemisection lesion 3 months earlier. Labeled tract ends at level of lesion (straight arrow). Growth of CST axons is difficult to discern at low magnification because of the punctate nature of the WGA-HRP TMB-labeled reaction product. Occasional artifactual labeling is evident; this was edited out of images before quantification of CST density. Scale bar, $620 \mu \mathrm{m}$. $b$, At higher magnification, growth of corticospinal axons in NT-3 graft recipient is visible. Numerous punctate, extremely fine granules of WGA-HRP TMB-labeled reaction product are present in host gray matter $(g r)$, ventral to lesioned CST; examples are indicated by arrows. Scale bars: $b, c, 250 \mu \mathrm{m}$. $c$, Control-grafted subjects show significantly less growth of CST axons in ventral gray matter ( $g r$ ) compared with NT-3-grafted subjects. $d$, The distribution of WGA-HRP TMB-labeled reaction product is best illustrated in camera lucida drawing. Reaction product observed by focusing through the full thickness of 35- $\mu \mathrm{m}$-thick sections is demonstrated. Extensive corticospinal axon growth is visible in NT-3 graft recipient at and distal to the lesion site. Lesion and graft $(g)$ site are outlined by dashed line and arrows. gr, Gray matter; $w$, ventral white matter. Scale bars: $d, e, 330 \mu \mathrm{m}$. $e$, Significantly less growth is evident in control-grafted subject.

motor deficits result from complete spinal cord transections in rats (Basso et al., 1995). Thus, ventral pathways contribute significantly to motor function, either independently of, or more likely synergistically with, dorsal pathways. Important ventral projections include the vestibulospinal, reticulospinal, and propriospinal projections, and the small ventral corticospinal projection (Paxinos, 1995). It is unlikely that the functional recovery found in Experiment 2 resulted from ventral corticospinal pathways, because quantification of labeled axons in this pathway showed no difference between NT-3-grafted and lesioned control subjects, and axons of the ventral pathway were not found to sprout in a manner that differed from control lesioned subjects (see Results). The present findings also highlight the intrinsic capacity of the spinal locomotor generator (Grillner, 1986) to produce relatively simple motor behaviors after removal of many, but not all, supraspinal inputs.

Previously it has been reported that the delivery of a single dose of NT-3 at the time of a spinal cord lesion induced sprouting of corticospinal axons (Schnell et al., 1994). In the present study,
NT-3 secreted continuously by genetically modified cells for 3 months induced growth of corticospinal axons both at and caudal to the site of a spinal cord injury. Of note, corticospinal axons extended only through host gray matter. Axons did not extend through host white matter either dorsal or ventral to the injury site, consistent with previous observations that CNS white matter is a nonconducive substrate for axon growth (Schnell et al., 1994; Cheng et al., 1996). Axons extended for distances of $8 \mathrm{~mm}$ caudal to the injury site but not further, possibly corresponding to the distance that NT-3 diff used from grafts. Intact ventral CST axons did not extend axons into the host gray matter, suggesting that injury to CST axons may be a necessary event to induce responsiveness to NT-3. Developing corticospinal axons express the specific high-affinity NT-3 receptor trkC (Yee and O'Leary, 1996), and corticospinal motor neuronal degeneration is preventable by NT-3 (Giehl and Tetzlaff, 1996). Thus, specific activation of trkC receptors on CST axons is a mechanism likely to account for NT-3 responsiveness in this experiment.

Injured CST axons did not penetrate either NT-3-producing or 


\section{Corticospinal Tract Sprouting}

Figure 7. Quantification of corticospinal axon growth. A significant increase in corticospinal axon growth is evident in NT-3-grafted subjects compared with control uninfected fibroblast grafted animals at the lesion site, $4 \mathrm{~mm}$ and $8 \mathrm{~mm}$ distal to the lesion. Differences are not significant $12 \mathrm{~mm}$ caudal to the lesion site. ${ }^{*} p<0.05$; ** $p<0.01$; *** $p<$ 0.005 .

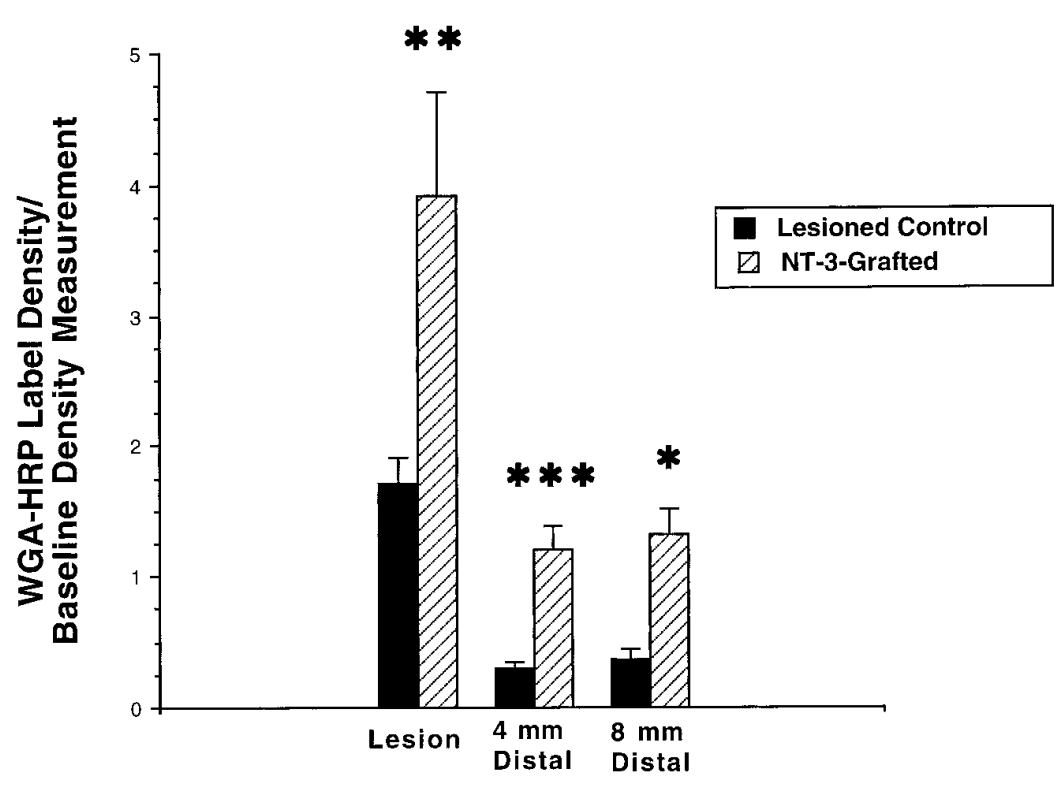

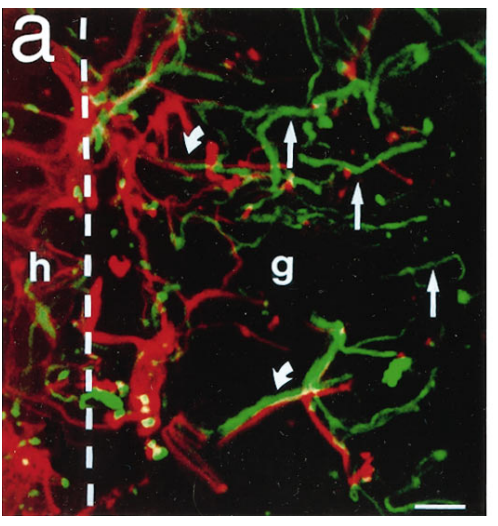

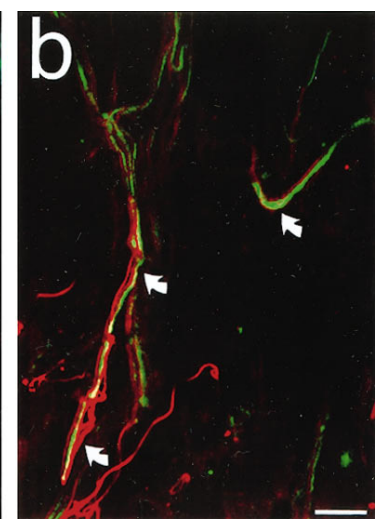

Figure 8. Association of axons at host/graft interface with glial processes. $a$, Sections double-labeled for NF (green) and GFAP (red), visualized by confocal microscopy, show upregulation of glial activity at the host/graft interface (interface indicated by dashed line). $h$, Host; $g$, graft. Interestingly, many penetrating axons are intimately associated with host glial processes (curved arrows), whereas other axons are unassociated with glial processes (straight arrows). $b, c$, This axonal/glial association persists beyond the host/graft interface and into the graft, although GFAPlabeled processes rarely penetrate grafts deeply. Identical axon-glial associations are observed in NT-3 and control grafts. Scale bars: a, $25 \mu \mathrm{m}$; b, $25 \mu \mathrm{m}$; c, $10 \mu \mathrm{m}$.

control fibroblast cell grafts, despite the fact that the presence of NT-3-secreting cell grafts substantially augmented CST growth in host gray matter. This suggests either that the collagen/fibronectin extracellular matrix of the graft was nonconducive to corticospinal axon growth or that host glial responses at the host/graft interface inhibited axon penetration into the graft. Double-labeling for NF and GFAP indicated that several noncorticospinal axons successfully penetrated both NT-3 and control grafts and that these axons were frequently associated with glial processes. In other cases, penetrating axons were not associated with glial processes. Although upregulation of GFAP immunoreactivity clearly occurred at the graft/host interface, this activity was not sufficient to block the penetration of axons labeled for NF into grafts. Thus, glial responses did not generally present an impenetrable "wall" to growing axons, and in many cases glial processes were intimately associated with penetrating axons. Consistent with recent observations from other studies, glial responses after CNS injury may not be uniformly inhibitory (McKeon et al., 1991; Silver, 1994) to axon growth and could in fact support or guide axon growth (Kawaja and Gage, 1991). Other extracellular molecules expressed at the injury site, such as chondroitin sulfate proteoglycan (Katoh-Semba et al., 1995; Emerling and Lander, 1996) or microglial-associated molecules (Fitch et al., 1996), may account for blockade of corticospinal axon penetration into grafts. Alternatively, the collagen/fibronectin substrate of the graft itself may be nonconducive to corticospinal axon growth. Developmental and in vitro studies clearly indicate that different classes of axons exhibit specific preferences for various growth substrates (Schinstine and Cornbrooks, 1990; Emerling and Lander, 1996; Halfter, 1996), and injured CNS axons exhibit similar properties (Richardson et al., 1980; Aguayo et al., 1982; Woerly, 1993). The identification of optimal combinations of neurotrophic factors and growth substrates may be a useful strategy for enhancing growth of CNS axons after injury.

Immunolabeling to detect growth from axons in projections other than the corticospinal system did not reveal specific responses to cellularly delivered NT-3. NF and p75 immunolabeling showed no quantitative difference in axon penetration into NT-3-secreting and nontransduced fibroblast grafts. Similarly, specific labeling for serotonin (raphaespinal projections), $\mathrm{TH}$ and DBH (cerulospinal projections), ChAT (ventral horn motor and other axons), CGRP (dorsal root efferents), and Substance P (dorsal root c-fibers) showed no specific responses from these systems. Qualitative analysis of patterns of immunolabeling for these markers also failed to disclose specific alterations in growth patterns in the host spinal cord adjacent to the injury site when NT-3-secreting and noninfected fibroblast grafts were compared. Specific immunolabels for several other supraspinal projections, including the rubrospinal, vestibulospinal, and reticulospinal systems, are not available, and the responses of these systems to cellularly delivered NT-3 were therefore not determined in this 

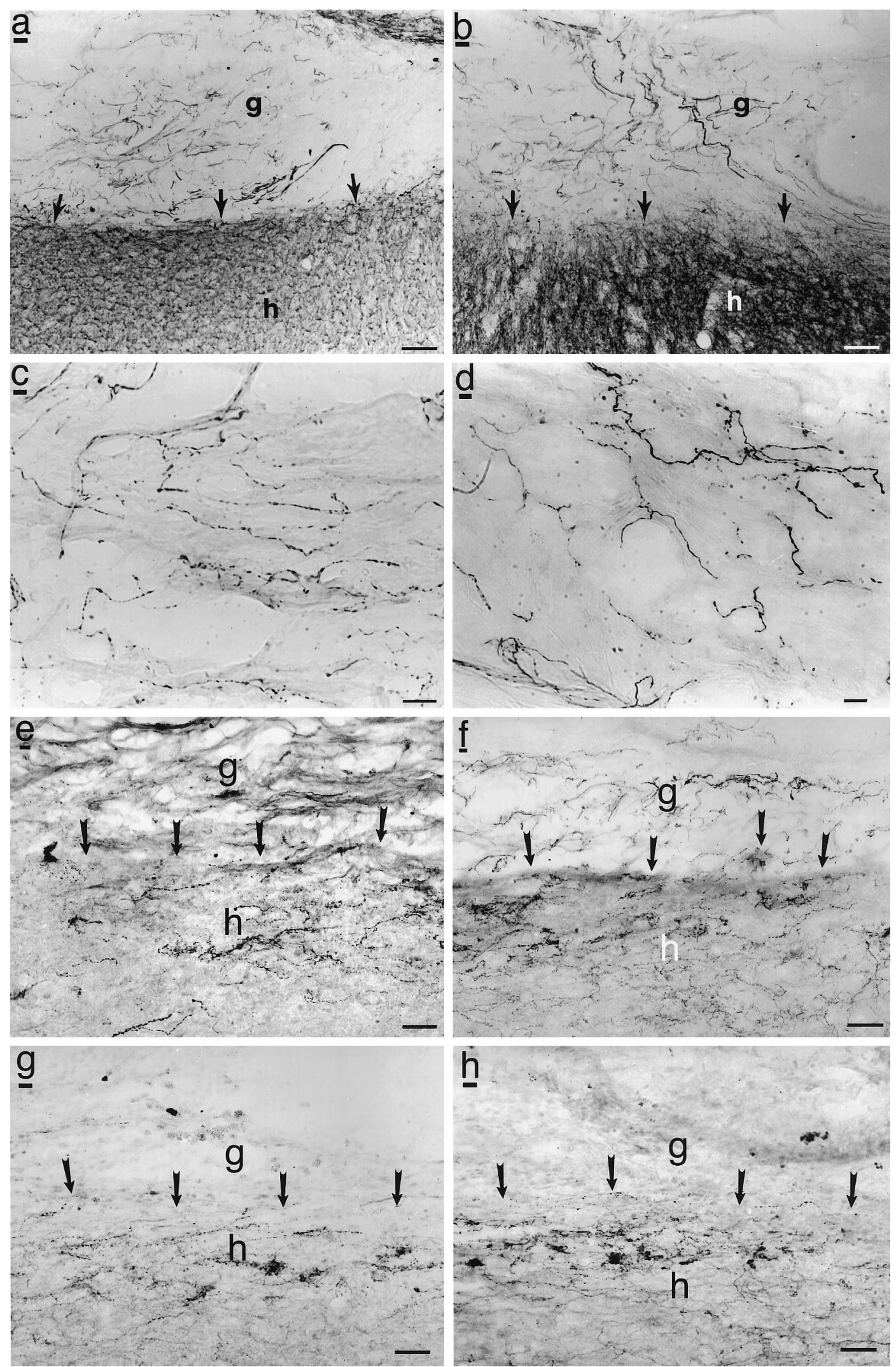

Figure 9. Immunolabeling of grafts and graft/host interface. NF immunolabel shows similar degree of axon penetration into $(a)$ NT-3 and $(b)$ control grafts. $g$, Graft; $h$, host. Arrows indicate host/graft interface. Scale bars: $a, b, 25 \mu \mathrm{m}$. Similarly, NT-3 $(c)$ and control $(d)$ grafts are equally penetrated by sensory axons extending from the dorsolateral fasciculus (CGRP immunolabel). Scale bars: $c, d, 7 \mu$ m. Raphaespinal axons modestly penetrate NT-3-secreting $(e)$ and control grafts $(f)$ to an equal extent. Scale bar, $12 \mu \mathrm{m}$. Few TH-labeled axons penetrate either NT-3 $(g)$ or control $(h)$ grafts. Scale bar, $12 \mu \mathrm{m}$. Penetration of ChAT, DBH, and p75 receptor-labeled axons also shows no difference between NT-3 and control grafts (data not shown). 


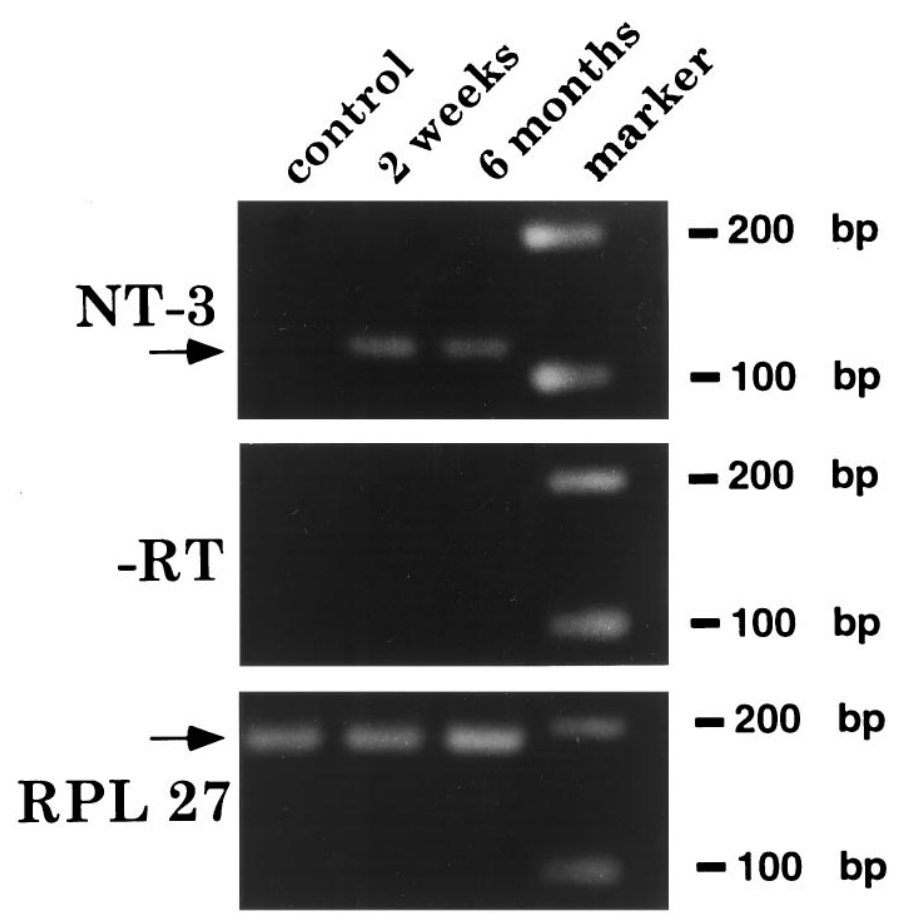

Figure 10. In vivo NT-3 transgene expression. RT-PCR indicates sustained human NT-3 transgene expression for at least 6 months after in vivo grafting. NT-3-secreting cells were freshly dissected from the spinal cord. Data are shown from animals at 2 weeks and 6 months after transplantation. For controls, (1) omission of RT $(-R T)$ from the reaction mixture shows loss of hNT-3 mRNA signal, as expected, (2) levels of expression of the housekeeping gene RPL 27 are similar in all groups, and (3) RT-PCR of a cord without a graft (control, lane 1) does not show amplification with the human NT-3 specific primer.

experiment. Recently it has been reported that the co-infusion of BDNF and NT-3 to the completely transected spinal cord elicits modest growth responses from vestibulospinal, reticulospinal, and rubrospinal axons (Xu et al., 1995); the dependency of these responses on either of the individual trophic factors, or the combined factors, has yet to be determined. Neurons of the locus ceruleus have also been reported to exhibit NT-3 responsiveness (Arenas and Persson, 1994), as have primary Ia sensory afferent projections (Klein et al., 1994; Tessarollo et al., 1994; Kucera et al., 1995a,b; Lindsay, 1996). Responses from these systems were not detected in the present experiment, a finding that could be related to a lack of appropriate receptor expression by these axons after injury in the adult spinal cord, to the amount of NT-3 produced by the graft, or to a lack of permissiveness of the collagen/fibronectin substrate of the graft to growth of these axons.

In previous studies we reported that grafts of NGF-transduced fibroblasts to the lesioned spinal cord promoted significant and specific growth of primary sensory axons, supraspinal cerulospinal axons, and putative local motor axons (Tuszynski et al., 1996, 1997). Populations of axons that respond to NT-3- and NGFsecreting grafts are therefore distinct, indicating that injured axons of the adult spinal cord retain robust and specific responsiveness to these neurotrophins.

The identification of mechanisms underlying functional recovery after experimental spinal cord injury requires characterization of responses from several diverse motor and sensory systems affected by the injury and characterization of alterations in the function of spinal locomotor pattern generators. Although this is a challenging task, several previous observations provide potential mechanisms of partial functional recovery after cellular delivery of NT-3 in the present experiment. (1) Duffy et al. (1990) reported that functional recovery in the regenerated lizard spinal cord is mediated by formation of short polysynaptic projections from injured axons to caudal motor neuron pools, rather than by long-distance regrowth of axons. Furthermore, stimulation of cortical motor neurons in intact cats (Kostyuk and Vasilenko, 1978) or after lesions of the corticospinal projection (Alstermark and Sasaki, 1985) generates excitation of spinal motor neurons through local propriospinal axon relays. Thus the partial functional recovery observed in this experiment may be mediated by excitation of distal motoneuron pools via regrown corticospinal projections propagating excitation through polysynaptic relays. (2) Corticospinal axons influence the intrinsic spinal locomotor pattern generator (Grillner, 1986; Leonard and Goldberger, 1987). Regrowing corticospinal projections in this experiment may have modulated the function of more rostrally located components of the spinal pattern generator rather than directly reinnervated lumbar motoneurons. (3) Regrowing corticospinal axons may interact with other spinal projection systems at lower thoracic levels that modulate locomotor function. For example, sprouting of serotonergic systems can influence functional recovery in some lesion paradigms (Bregman et al., 1993, 1995), and sprouting/regenerating corticospinal projections may interact with these motor system modulators (Thor et al., 1993). Electrophysiological studies can examine these possibilities.

Two other reports of partial functional recovery resulting from regrowth of host projections after spinal cord injury have been published recently (Bregman et al., 1995; Cheng et al., 1996). In one approach, CNS myelin-associated growth inhibitors were neutralized (Bregman et al., 1995), resulting in regrowth of axons through host white matter. Corticospinal axons putatively mediated functional recovery after these partial spinal cord injuries, because lesions of the sensorimotor cortex abolished recovery. This finding is consistent with the present study, in that we observed specific responses from corticospinal systems in response to cellularly delivered NT-3 together with partial functional recovery. In a second study, delivery of acidic fibroblast growth factor reportedly generated growth responses from all supraspinal systems studied, resulting in functional recovery after complete spinal cord transections (Cheng et al., 1996). Regenerating axons in the latter experiment were specifically directed toward host gray matter to avoid myelin-based inhibitors. These findings too are consistent with the present report, in that injured corticospinal axons, presented with a choice between using the graft, the host white matter, or the host gray matter as a growth substrate, used only host gray matter. These findings highlight the importance of defining appropriate growth terrains for injured adult CNS axons and of identifying specific growth-promoting neurotrophic factors.

\section{REFERENCES}

Aguayo A, David S, Richardson P, Bray G (1982) Axonal elongation in peripheral and central nervous system transplants. Adv Cell Neurobiol 3:215-234.

Akbarian S, Grusser OJ, Guldin WO (1994) Corticofugal connections between the cerebral cortex and brainstem vestibular nuclei in the macaque monkey. J Comp Neurol 339:421-437.

Alstermark B, Sasaki S (1985) Integration in descending motor pathways controlling the forelimb in the cat. 13. Corticospinal effects in shoulder, elbow, wrist and digit motoneurones. Exp Brain Res 59:353-364. 
Arenas E, Persson H (1994) Neurotrophin-3 prevents the death of adult central noradrenergic neurons in vivo. Nature 367:368-371.

Basso DM, Beattie MS, Bresnahan JC (1995) A sensitive and reliable locomotor rating scale for open field testing in rats. J Neurotrauma 12:1-21.

Beloozerova IN, Sirota MG (1993) The role of the motor cortex in the control of accuracy of locomotor movements in the cat. J Physiol (Lond) 461:1-25.

Bregman BS, Kunkel-Bagden E, Reier PJ, Dai HN, McAtee M, Gao D (1993) Recovery of function after spinal cord injury: mechanisms underlying transplant-mediated recovery of function differ after spinal cord injury in newborn and adult rats. Exp Neurol 123:3-16.

Bregman BS, Kunkel-Bagden E, Schnell L, Dai HN, Gao D, Schwab ME (1995) Recovery from spinal cord injury by antibodies to neurite growth inhibitors. Nature 378:498-501.

Bussieres N, Dubuc R (1992) Phasic modulation of vestibulospinal neuron activity during fictive locomotion in lampreys. Brain Res 575:174-179.

Cheng H, Yihai C, Olson L (1996) Spinal cord repair in adult paraplegic rats: partial restoration of hind limb function. Science 273:510-513.

Chomczynski P, Sacchi N (1987) Single-step method of RNA isolation by acid guanidium thiocyanate-phenol-chloroform extraction. Anal Biochem 162:156-159.

Clark JB, Bellegarrigue RB, Salcman M (1985) Gunshot wound to the pons with functional neuroanatomical and electrophysiological correlation. Neurosurgery 16:607-611.

Drew T, Jiang W, Kably B, Lavoie S (1996) Role of the motor cortex in the control of visually triggered gait modifications. Can J Physiol Pharmacol 74:426-442.

Duffy MT, Simpson SB, Liebich DR, Davis BM (1990) Origin of spinal cord axons in the lizard regenerated tail: supernormal projections from local spinal neurons. J Comp Neurol 293:208-222.

Eidelberg E, Nguyen LH, Polich R, Walden JG (1989) Transsynaptic degeneration of motoneurones caudal to spinal cord lesions. Brain Res Bull 22:39-45.

Emerling DE, Lander AD (1996) Inhibitors and promoters of thalamic neuron adhesion and outgrowth in embryonic neocortex: functional association with chondroitin sulfate. Neuron 17:1089-1100.

Farmer SF, Swash M, Ingram DA, Stephens JA (1993) Changes in motor unit synchronization following central nervous lesions in man. J Physiol (Lond) 463:83-105.

Fehlings MG, Tator CH (1995) The relationships among the severity of spinal cord injury, residual neurological function, axon counts, and counts of retrogradely labeled neurons after experimental spinal cord injury. Exp Neurol 132:220-228.

Fetcho JR (1992) The spinal motor system in early vertebrates and some of its evolutionary changes. Brain Behav Evol 40:82-97.

Fitch MT, Theriault E, Mortin-Toth S, Silver J (1996) Proteoglycan upregulation following spinal cord injury is closely associated with activated microglia/macrophages. Soc Neurosci Abstr 22:1231.

Frisen J, Arvidsson U, Lindholm T, Fried K, Verge VM, Cullheim S, Hokfelt T, Risling M (1993) trkC expression in the injured rat spinal cord. NeuroReport 5:349-352.

Giehl KM, Tetzlaff W (1996) BDNF and NT-3, but not NGF, prevent axotomy-induced death of rat corticospinal neurons in vivo. Eur J Neurosci 8:1167-1175.

Goldberger ME, Bregman BS, Vierck JR, Brown M (1990) Criteria for assessing recovery of function after spinal cord injury: behavioral methods. Exp Neurol 107:113-117.

Gossard JP, Floeter MK, Degtyarenko AM, Simon ES, Burke RE (1996) Disynaptic vestibulospinal and reticulospinal excitation in cat lumbosacral motoneurons: modulation during fictive locomotion. Exp Brain Res 109:277-288.

Grillner S (1986) Locomotion in spinal vertebrates. Physiology and pharmacology. In: Development and plasticity of the mammalian spinal cord (Goldberger ME, Gorio A, Murray M, eds), pp 311-321. Padova, Italy: Liviana.

Grillner S, Deliagina T, Ekeberg O, el Manira A, Hill RH, Lansner A, Orlovsky GN, Wallen P (1995) Neural networks that co-ordinate locomotion and body orientation in lamprey. Trends Neurosci 18:270-279.

Halfter W (1996) The behavior of optic axons on substrate gradients of retinal basal lamina proteins and merosin. J Neurosci 16:4389-4401.

Harmann PA, Chung K, Briner RP, Westlund KN, Carlton SM (1988)
Calcitonin gene-related peptide (CGRP) in the human spinal cord: alight and electron microscopic analysis. J Comp Neurol 269:371-380.

Iwakiri H, Oka T, Takakusaki K, Mori S (1995) Stimulus effects of the medial pontine reticular formation and the mesencephalic locomotor region upon medullary reticulospinal neurons in acute decerebrate cats. Neurosci Res 23:47-53.

Joosten EA, Schuitman RL, Vermelis ME, Dederen PJ (1992) Postnatal development of the ipsilateral corticospinal component in rat spinal cord: a light and electron microscopic anterograde HRP study. J Comp Neurol 326:133-146.

Katoh-Semba R, Matsuda M, Kato K, Oohira A (1995) Chondroitin sulphate proteoglycans in the rat brain: candidates for axon barriers of sensory neurons and the possible modification by laminin of their actions. Eur J Neurosci 7:613-621.

Kawaja M, Gage FH (1991) Reactive astrocytes are substrates for the growth of adult CNS axons in the presence of elevated levels of nerve growth factor. Neuron 7:1019-1031.

Klein R, Silos-Santiago I, Smeyne RJ, Lira SA, Brambilla R, Bryant S, Zhang L, Snider WD, Barbacid M (1994) Disruption of the neurotrophin-3 receptor gene trkC eliminates Ia muscle afferents and results in abnormal movements. Nature 368:249-251.

Kostyuk PG, Vasilenko DA (1978) Propriospinal neurones as a relay system for transmission of corticospinal influences. J Physiol (Paris) $74: 247-250$.

Kucera J, Ernfors P, Walro J, Jaenisch R (1995a) Reduction in the number of spinal motor neurons in neurotrophin-3 deficient mice. Neuroscience 69:321-330.

Kucera J, Fan G, Jaenisch R, Linnarsson S, Ernfors P (1995b) Dependence of developing group Ia afferents on neurotrophin-3. J Comp Neurol 363:307-320.

Kunkel-Bagden E, Dai HN, Bregman BS (1993) Methods to assess the development and recovery of locomotor function after spinal cord injury in rats. Exp Neurol 119:153-164.

Leonard CT, Goldberger ME (1987) Consequences of damage to the sensorimotor cortex in neonatal and adult cats. I. Sparing and recovery of function. Dev Brain Res 32:1-14.

Lindsay RM (1996) Role of neurotrophins and trk receptors in the development and maintenance of sensory neurons: an overview. Philos Trans R Soc Lond [Biol] 351:365-373.

Maisonpierre PC, Belluscio L, Squinto S, Ip NY, Furth ME, Lindsay RM, Yancopoulos GD (1990) Neurotrophin-3: a neurotrophic factor related to NGF and BDNF. Science 247:1446-1451.

Maisonpierre PC, Le Beau MM, Espinosa R, Ip NY, Belluscio L, de la Monte SM, Squinto S, Furth ME, Yancopoulos GD (1991) Human and rat brain-derived neurotrophic factor and neurotrophin-3: gene structures, distributions and chromosomal localizations. Genomics 10:558-568.

Marlinsky VV, Voitenko LP (1992) Participation of the medial reticular formation of the medulla oblongata in the supraspinal control of locomotor and postural activities in the guinea pig. Neurosci Behav Physiol 22:336-342.

Marlinsky VV (1992) Activity of lateral vestibular nucleus neurons during locomotion in the decerebrate guinea pig. Exp Brain Res 90:583-588

Marple-Horvat DE, Amos AJ, Armstrong DM, Criado JM (1993) Changes in the discharge patterns of cat motor cortex neurones during unexpected perturbations of on-going locomotion. J Physiol (Lond) 462:87-113.

McKeon RJ, Schreiber RC, Rudge JS, Silver J (1991) Reduction of neurite outgrowth in a model of glial scarring following CNS injury is correlated with expression of inhibitory molecules on reactive astrocytes. J Neurosci 11:3398-3411.

McNeill DL, Carlton S, Hulsebosch CE (1991) Intraspinal sprouting of calcitonin gene-related peptide containing primary afferents after deafferentation in the rat. Exp Neurol 114:321-329.

Merlio JP, Ernfors P, Jaber M, Persson H (1992) Molecular cloning of rat trkC and distribution of cells expressing mRNAs for members of the trk family in the rat central nervous system. Neuroscience 51:513-532.

Mesulam M-M (1978) Tetramethyl benzidine for horseradish peroxidase neurohistochemistry: a non-carcinogenic blue reaction-product with superior sensitivity for visualizing neural afferents and efferents. J Histochem Cytochem 26:106-117.

Midha R, Fehlings MG, Tator CH, Saint-Cyr JA, Guha A (1987) Assessment of spinal cord injury by counting corticospinal and rubrospinal neurons. Brain Res 410:299-308. 
Miller LE, Houk JC (1995) Motor co-ordinates in primate red nucleus: preferential relation to muscle activation versus kinematic variables. J Physiol (Lond) 488:533-548.

Muragaki Y, Timothy N, Leight S, Hempstead BL, Chao MV, Trojanowski JQ, Lee VM (1995) Expression of trk receptors in the developing and adult human central and peripheral nervous system. J Comp Neurol 356:387-397.

Nathan PW (1994) Effects on movement of surgical incisions into the human spinal cord. Brain 117:337-346.

Netz J, Homberg V (1992) Intact conduction of fastest corticospinal efferents is not sufficient for normal voluntary muscle strength: transcranial motor cortex stimulation in patients with tetraplegia. Neurosci Lett 146:29-32.

Paxinos G, Watson C (1986) The rat brain in stereotaxic coordinates, 2nd Ed. San Diego: Academic.

Paxinos G (1995) The rat nervous system, 2nd Ed. Sydney: Academic.

Perreault MC, Drew T, Rossignol S (1993) Activity of medullary reticulospinal neurons during fictive locomotion. J Neurophysiol 69:2232-2247.

Pflieger JF, Cabana T (1996) The vestibular primary afferents and the vestibulospinal projections in the developing and adult opossum, Monodelphis domestica. Anat Embryol (Berl) 194:75-88.

Richardson PM, McGuiness UM, Aguayo AJ (1980) Axons from CNS neurons regenerate into PNS grafts. Nature 284:264-265.

Schinstine M, Cornbrooks CJ (1990) Axotomy enhances the outgrowth of neurites from embryonic rat septal-basal forebrain neurons on a laminin substratum. Exp Neurol 108:10-22.

Schnell L, Schneider R, Kolbeck R, Barde YA, Schwab ME (1994) Neurotrophin-3 enhances sprouting of corticospinal tract during development and after adult spinal cord lesion. Nature 367:170-173.

Senut M-C, Tuszynski MH, Raymon HK, Suhr ST, Liou NH, Jones KR, Reichardt LF, Gage FH (1995) Regional differences in responsiveness of adult CNS axons to grafts of cells expressing human neurotrophin-3. Exp Neurol 135:36-55.

Silver J (1994) Inhibitory molecules in development and regeneration. J Neurol 242:S22-S24.

Skofitsch G, Jacobwitz DM (1985) Quantitative distribution of calcitonin gene-related peptide in the rat central nervous system. Peptides 6:1069-1073.

Spoor F, Wood B, Zonneveld F (1994) Implications of early hominid labyrinthine morphology for evolution of human bipedal locomotion. Nature 369:645-648.

Tessarollo L, Vogel KS, Palko ME, Reid SW, Parada LF (1994) Targeted mutation in the neurotrophin-3 gene results in loss of muscle sensory neurons. Proc Natl Acad Sci USA 91:11844-11848.
Thor KB, Nickolaus S, Helke CJ (1993) Autoradiographic localization of 5-hydroxytryptamine 1A, 5-hydroxytryptamine $1 \mathrm{~B}$ and 5-hydroxytryptamine $1 \mathrm{C} / 2$ binding sites in the rat spinal cord. Neuroscience 55:235-252.

Tuszynski MH, Peterson DA, Ray J, Baird A, Nakahara Y, Gage FH (1994) Fibroblasts genetically modified to produce nerve growth factor induce robust neuritic ingrowth after grafting to the spinal cord. Exp Neurol 126:1-14.

Tuszynski MH, Gabriel K, Gage FH, Suhr S, Meyer S, Rosetti A (1996) Nerve growth factor delivery by gene transfer induces differential outgrowth of sensory, motor and noradrenergic neurites after adult spinal cord injury. Exp Neurol 137:157-173.

Tuszynski MH, Murai K, Blesch A, Grill R, Miller I (1997) Functional characterization of NGF-secreting cell grafts to the acutely injured spinal cord. Cell Transplant, in press.

Vinay L, Grillner S (1993) The spino-reticulo-spinal loop can slow down the NMDA-activated spinal locomotor network in lamprey. NeuroReport 4:609-612.

Vinay L, Padel Y, Bourbonnais D, Steffens H (1993) An ascending spinal pathway transmitting a central rhythmic pattern to the magnocellular red nucleus in the cat. Exp Brain Res 97:61-70.

Whishaw IQ, Kolb B (1988) Sparing of skilled forelimb reaching and corticospinal projections after neonatal motor cortex removal or hemidecortication in the rat: support for the Kennard doctrine. Brain Res 451:97-114.

Whishaw IQ, Tomie J, Ladowsky RL (1990) Red nucleus lesions do not affect limb preference or use, but exacerbate the effects of motor cortex lesions on grasping in the rat. Behav Brain Res 40:131-144.

Whishaw IQ, Pellis SM, Gorny B, Kolb B, Tetzlaff W (1993) Proximal and distal impairments in rat forelimb use in reaching follow unilateral pyramidal tract lesions. Behav Brain Res 56:59-76.

Widajewicz W, Kably B, Drew T (1994) Motor cortical activity during voluntary gait modifications in the cat. II. Cells related to the hindlimbs. J Neurophysiol 72:2070-2089.

Woerly S (1993) Hydrogels for neural tissue reconstruction and transplantation. Biomaterials 14:1056-1058.

Xu XM, Guenard V, Kleitman N, Aebischer P, Bunge MB (1995) A combination of BDNF and NT3 promotes supraspinal axonal regeneration in Schwann cell grafts in adult rat thoracic spinal cord. Exp Neurol 134:261-272.

Yee KT, O'Leary D (1996) NT-3 and trkC expression patterns suggest their role in the development of corticospinal axon projections to the brainstem and spinal cord. Soc Neurosci Abstr 22:1468. 